Canadian

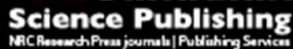

Canadian Geotechnical Journal Revue canadienne de géotechnique

On the role of normal boundary condition in interface shear test for the determination of skin friction along pile shaft

\begin{tabular}{|r|l|}
\hline Journal: & Canadian Geotechnical Journal \\
\hline Manuscript ID & cgj-2016-0312.R1 \\
\hline Manuscript Type: & Article \\
\hline Date Submitted by the Author: & 06-Dec-2016 \\
\hline Complete List of Authors: & $\begin{array}{l}\text { Wang, Jianfeng; City University of Hong Kong, } \\
\text { Liu, Su; City University of Hong Kong, Department of Architecture and Civil } \\
\text { Engineering } \\
\text { Cheng, Yi Pik; University College London }\end{array}$ \\
\hline Keyword: & $\begin{array}{l}\text { pile penetration, interface shear test, constant normal stiffness (CNS), } \\
\text { particle breakage, discrete element method (DEM) simulation }\end{array}$ \\
\hline &
\end{tabular}

SCHOLARONEm

Manuscripts 


\title{
On the role of normal boundary condition in interface shear test for the determination of skin friction along pile shaft
}

\author{
Jianfeng Wang ${ }^{1}$, Su Liu ${ }^{2}$ and Yi Pik Cheng ${ }^{3}$ \\ ${ }^{1}$ Associate Professor \\ Department of Architecture and Civil Engineering, \\ City University of Hong Kong, Hong Kong \\ ${ }^{2}$ Graduate Research Assistant \\ Department of Architecture and Civil Engineering, \\ City University of Hong Kong, Hong Kong \\ ${ }^{3}$ Senior Lecturer \\ Department of Civil, Environmental and Geomatic Engineering, \\ University College London, London, UK
}

\section{Corresponding Author}

Dr. Jianfeng Wang

Department of Architecture and Civil Engineering

City University of Hong Kong, Hong Kong

Tel: (852) 34426787, Fax (852) 27887612

E-mail: jefwang@cityu.edu.hk 


\begin{abstract}
This paper presents numerical results from a two-dimensional discrete element method (DEM) simulation study on the influence of lateral boundary condition on the shaft resistance of a pile driven into a crushable sand. The study was made by comparing the simulation results from the pile penetration test and the interface shear test employing parallel-bonded agglomerates for the modeling of particle breakage. The interface shear test was performed under three different types of normal boundary condition, namely, constant normal load (CNL), constant normal stiffness (CNS), and constant volume $(\mathrm{CV})$ boundary conditions. For the pile penetration test, a series of sampling windows were identified on the initial ground configuration to monitor the stress-strain, volume change and particle breakage behavior of particle groups located within the sampling windows. A detailed investigation is then made by comparing the behavior of particle groups with that from the interface shear test to find out which type of the normal boundary condition best describes the lateral boundary condition in the pile penetration test. It is found that the behavior of a particle group has reached the peak state below the pile tip and the critical state after it reaches the pile shaft. The influence of normal boundary condition on the stress ratio at the critical state is not obvious. The conventional interface shear test (i.e., CNL) can provide valuable information on the determination of skin friction along the pile shaft.
\end{abstract}

Key Words: pile penetration, interface shear test, constant normal stiffness (CNS), crushable sand, particle breakage, discrete element method (DEM) simulation 


\section{INTRODUCTION}

The mechanical behavior of soil-pile interface has a deciding influence on the overall reaction of driven piles in sand (Ooi and Carter 1987). The unit pile shaft resistance $\left(\tau_{\mathrm{f}}\right)$ could be described by the simple Coulomb failure criterion:

$$
\tau_{\mathrm{f}}=\left(\sigma_{\mathrm{rc}}^{\prime}+\Delta \sigma_{\mathrm{r}}^{\prime}\right) \tan \delta_{\mathrm{f}}
$$

where $\sigma_{\mathrm{rc}}$ is the long-term radial effective stress on the pile shaft after installation, $\Delta \sigma_{\mathrm{r}}$ is the change of radial effective stress due to dilation during loading, and $\delta_{\mathrm{f}}$ is soil-pile interface friction angle (Lehane et al. 1993, 2005; Chow et al. 1997). $\sigma_{\text {rc }}^{\prime}$ depends on the initial relative density, initial stress state, the relative position of the pile tip (Lehane 1992) and the number of load cycles (Gavin and O'Kelly 2007). Recent experimental investigation by Jardine et al. (2013) and DEM-based study by Liu and Wang (2016) have revealed $\sigma_{\text {rc }}$ can be expressed by a two dimensional function of the normalized vertical and horizontal distances from the pile tip as $\sigma_{\mathrm{rc}}^{\prime}=f(h / R, r / R) \cdot q_{\mathrm{b}}$, where $r$ is the relative offset from the pile axis, $h$ is the relative height from pile tip, $R$ is the pile radius, and $q_{\mathrm{b}}$ is the pile tip resistance. To investigate the radial stress change on shaft friction, White and Lehane (2004) performed a series of centrifuge tests of displacement piles in sand. Cyclic loading history was found to be the key factors controlling friction fatigue. The interface friction angle depends on the mechanical properties, particle-scale morphology and size of sand, the material of pile shaft and its roughness (Uesugi et al. 1988; Yang et al. 2010; Tehrani et al. 2016).

Using interface shear tests to investigate the pile shaft behavior remains popular because of the high cost of field and centrifuge tests. In the conventional interface shear test, the sand sample is sheared monotonically under the condition of 
constant normal load (CNL). Nonetheless, the normal stress acting on the soil-pile interface may increase or decrease in field tests, because the pile is constrained on both sides and dilation or contraction may occur with shearing. This phenomenon could be more precisely modeled by the constant normal stiffness (CNS) boundary condition. In order to model this type of boundary condition for obtaining more rational and economical design parameters, a CNS interface shear test apparatus was designed and fabricated by Johnston et al. (1987), Ooi and Carter (1987), Tabucanon et al. (1995), Porcina et al. (2003), Jiang et al. (2004), DeJong et al. (2006), and Di Donna et al. (2016). The test results showed that the normal stress and shear stress increase with shear-induced dilation until the residual condition is attained. Additionally, constant volume $(\mathrm{CV})$ boundary condition is often used to simulate the fully undrained condition. Fakharian and Evgin (1997) generalized the CNL, CV and CNS boundary conditions using $k_{\mathrm{n}}=0, k_{\mathrm{n}}=\infty$ and $k_{\mathrm{n}}=$ constant, where $k_{\mathrm{n}}$ is the stiffness in the direction normal to the interface. Given the same cyclic loading history, the increase in radial stress can be reasonably estimated by the normal stress variation in CNS interface shear test if the stiffness of the normal boundary conditions imposed approximates radial stiffness for the sand mass surrounding the pile shaft (Lehane and White 2005).

The discrete element method (DEM) which allows full access to the particlescale force and displacement information, provides an alternative way to investigate interface shear test. Frost et al. (2002) conducted a group of 2D DEM simulations of particulate-continuum interface which consists of clumps and sawtooth textured surface (Fig. 1e). The coupled effect of surface roughness and hardness, which was modeled indirectly by changing the friction coefficient of the particle-continuum interface, on the interface shear strength was discussed. Wang et al. (2007a, 2007b) 
made detailed 2D DEM analyses on the effects of relative particle to surface geometry on the strength behavior of an interphase system. A failure criterion for estimating the shear strength of interphase systems was presented based on the contact force anisotropy of those particles that touch the interface. Peng et al. (2014) quantified the influence of normal boundary condition with uncrushable disks. The normal stiffness constraining the soil was varied by changing the normal stiffness of the wall. During the shearing process, the overall stiffness would change as the contact number on the wall varied. To some extent, this is not a real CNS boundary condition.

In previous related studies (Wang and Zhao 2014; Liu and Wang 2016), the authors made a detailed discrete-continuum analysis of the pile penetration behavior based on the 2D DEM simulation results. The stress and strain data provided by the model were mainly used to demonstrate the effects of in-situ stress field, initial soil density, particle crushability, the ratio of pile diameter to median particle diameter and the ratio of model width to pile diameter. The current study, on the basis of those previous studies, aims to study the effects of normal boundary condition in interface shear tests and the initial state of sand on the pile shaft resistance, and then provide information on selecting the type of interface shear test for the estimation of the skin friction along pile shaft. This will be achieved by developing 2D DEM models of interface shear test under CNL, CNS and CV conditions with crushable particles, and comparing the simulation results of model pile with interface shear test. The CNS boundary condition is modeled by a servo-mechanism which controls the velocity of the upper wall.

\section{NUMERICAL METHOD AND MODEL}

Simulations were carried out using PFC $^{2 \mathrm{D}}$ program (Itasca Consulting Group Inc. 2008). Particle breakage is allowed by the disintegration of agglomerates, each of 
which is composed of 24-30 parallel-bonded elementary disks with diameters between 0.069-0.278 mm (Fig. 1d). The contact between two elementary disks within an agglomerate consists of three parts: a linear stiffness model, a slip model, and a parallel-bond model (Cheng et al. 2003; Wang and Yan 2012, 2013). A parallel-bond breaks if the normal or shear stress acting on the bond exceeds its corresponding bond strength. The conventional linear contact model with a slip failure mechanism will take effect after a parallel bond is broken. The crushability of agglomerates was defined by the parallel bond strength ( $\left.\mathrm{pb} \_\mathrm{s}\right)$.

The DEM model of penetration test is made up of a rectangular container filled with a well compacted, poly-dispersed assembly of round particles and a model pile with a triangular tip (two inclined planes each making an angle of $60^{\circ}$ with the horizontal) pushed gradually into the granular foundation. Taking advantage of the axial symmetry of the problem, only the right half of the model with a dimension of $240 \mathrm{~mm}(15 B) \times 480 \mathrm{~mm}(30 B)$ is used (Fig. 1a), where $B$ is the pile diameter equal to $16 \mathrm{~mm}$. The granular foundation consists of two zones: a crushable zone surrounding the pile and an uncrushable zone surrounding the crushable zone. The bold dash lines in Figure 1a highlight the boundary between two zones. The dimension of the crushable zone is $32 \mathrm{~mm}(2 B) \times 432 \mathrm{~mm}(27 B)$. Wang and Zhao (2014) demonstrated that this size is sufficient for accommodating the vast majority of particle breakage events induced by pile penetration. The granular material in the uncrushable zone is composed of rigid disks with diameters uniformly varying between $0.6 \mathrm{~mm}$ and 1.2 $\mathrm{mm}$. The pile shaft is made up of a rough surface with triangular asperities of equal size. The asperity height and width are $0.85 \mathrm{~mm}$ and $1.7 \mathrm{~mm}$ respectively (Fig. 1c). The friction coefficient of the pile tip and asperity walls comprising the pile shaft was set to 0.5 . The sample is compacted at an initial porosity of 0.2 with an artificially 
raised gravity acceleration of $100 \mathrm{~g}$, where $\mathrm{g}$ is the standard gravitational acceleration $\left(9.81 \mathrm{~m} / \mathrm{s}^{2}\right)$. According to its stress-strain behavior in a previous study (Liu and Wang 2016), the granular material with an initial porosity of 0.2 is a medium dense particulate material. To create a relatively uniform granular sample with a specified initial porosity, the multilayer under-compaction method (Jiang et al. 2003) was used to generate both the penetration and interface shear model. pb_s is set to $1 \times 10^{7} \mathrm{~N} / \mathrm{m}$ for high-crushable agglomerates, and $2 \times 10^{9} \mathrm{~N} / \mathrm{m}$ as an extreme case for agglomerates that would not be crushed. The justification of performing the plane strain penetration test was illustrated by comparing the theoretical prediction made on the assumption of plane strain condition with axisymmetric physical test results (Randolph et al. 1979). The validity of using 2D DEM model to represent the axisymmetric pile scenario was further verified by comparing the simulation results with experimental data from plane strain (White and Bolton 2004; Arshad et al. 2014) and axisymmetric (Jardine et al. 2013) calibration chambers tests in the previous related studies (Wang and Zhao 2014; Liu and Wang 2016).

The DEM model of interface shear test (Fig. 1e) consists of a $167.1 \mathrm{~mm}$ long, $15 \mathrm{~mm}$ high shear box filled with a mixture of agglomerates whose diameter also has a linear distribution in the range of $0.6 \mathrm{~mm}$ to $1.2 \mathrm{~mm}$. The bottom boundary is made up of a rough surface and two $30 \mathrm{~mm}$ long "dead zones" placed at the ends of the box. There is no particle-to-wall friction within the dead zones to avoid boundary effects. The rough surface consists of the same regular asperities adopted in the pile shaft surface. The sample is also compacted at an initial porosity of 0.2 under an initial confining stress of $0.5 \mathrm{MPa}$ or $1 \mathrm{MPa}$. By varying the value of $\mathrm{pb} s$, uncrushable (i.e., pb_s $=2 \times 10^{9} \mathrm{~N} / \mathrm{m}$ ), low-crushable (i.e., pb_s $=2 \times 10^{7} \mathrm{~N} / \mathrm{m}$ ) and high-crushable (i.e., pb_s $=1 \times 10^{7} \mathrm{~N} / \mathrm{m}$ ) samples were prepared. In a previous study (Wang and Zhao 2014), 
the simulation results of low-crushability and high-crushability sands agree well with the experimental data of Leighton Buzzard sand (LBS) and Dog's Bay sand (DBS), respectively.

The upper boundary is a servo-wall whose velocity is being adjusted in the whole process of shearing in order to obtain different boundary conditions. The shear displacement, which is produced by moving the bottom walls horizontally, is $15 \mathrm{~mm}$ at the end of the test. Parameters used in the model are listed in Table 1. In CNS tests, cylindrical cavity expansion theory is often used to calculate the value of normal stiffness (Tabucanon et al. 1995; Lehane et al. 2005; Peng et al. 2014), which is given by:

$$
k_{\mathrm{n}}=\frac{4 G}{B}
$$

where $G$ is the linear shear modulus of sand mass constraining the dilation. Normal stiffness in the studies of Tabucanon et al. (1995), Lehane et al. (2005) and Peng et al. (2014) ranges from $0.22 \times 10^{9}$ to $1.85 \times 10^{9} \mathrm{~Pa} / \mathrm{m}, 0.8 \times 10^{9}$ to $1.6 \times 10^{9} \mathrm{~Pa} / \mathrm{m}$ and $1 \times 10^{9}$ to $10 \times 10^{9} \mathrm{~Pa} / \mathrm{m}$, respectively. According to Equation (2), the normal stiffness for crushable and uncrushable soils should be different. However, in order to directly comparing the results of samples with different crushability under the same boundary condition, the normal stiffness for every sample is set to $2 \times 10^{9} \mathrm{~Pa} / \mathrm{m}$ in this study.

\section{CONSTANT NORMAL STIFFNESS BOUNDARY CONDITION IN DEM}

In CNL test, the normal stress applied on the top boundary was kept constant by adjusting the top wall velocity every timestep. In CV test, the top wall was fixed. 
In CNS test, the top wall velocity was adjusted every timestep to achieve a constant ratio of the variation of the normal stress to the variation of the displacement.

A schematic diagram of interface shear test under CNS boundary condition in DEM is shown in Figure 2. The upper boundary consists of a servo-wall connected to a virtual fixed wall via a virtual spring. The word "virtual" is used, because the virtual fixed wall and virtual spring actually do not exist in the DEM simulation. However, the ratio of the variation of the normal stress to the variation of the normal displacement at the servo-wall remains constant when it moves upward or downward. This behavior makes it as if there exists a spring and a fixed wall above the servo-wall.

Throughout the shearing process, the stiffness of the "virtual spring" on the servo-wall is kept constant by adjusting the servo-wall velocity using a numerical servo-mechanism which is called every timestep. It adjusts the wall velocity in such a way as to reduce the difference between the measured stiffness and the target stiffness. The servo-mechanism is implemented using the following algorithm.

The stress on and the displacement of the servo-wall are $\sigma_{i}^{\text {measured }}$ and $\Delta s_{i}^{\text {measured }}$, respectively, after the model has run for $i$ cycles. The stress on the servowall should be equal to the stress on the spring, which is

$$
\sigma_{i}^{\text {measured }}=k_{\mathrm{n}}\left(\Delta s_{i}^{\text {required }}+s_{0}\right)
$$

where $k_{\mathrm{n}}$ is the stiffness of the spring, $\Delta s_{i}^{\text {required }}$ is the required displacement of the servo-wall, and $s_{0}$ is the elongation of the spring due to the initial confining stress. The equation for $s_{0}$ is

$$
s_{0}=\sigma_{0} / k_{\mathrm{n}}
$$


where $\sigma_{0}$ is the initial confining stress on the servo-wall. Hence, the required displacement of the servo-wall is

$$
\Delta s_{i}^{\text {required }}=\left(\sigma_{i}^{\text {measured }}-\sigma_{0}\right) / k_{\mathrm{n}}
$$

So at the $i+1$ cycle, in order to keep the stiffness of the spring unchanged, the displacement of the servo-wall should be

$$
\Delta s_{i+1}^{\text {wall }}=\Delta s_{i}^{\text {required }}-\Delta s_{i}^{\text {measured }}=\left(\sigma_{i}^{\text {measured }}\right) / k_{\mathrm{n}}-\Delta s_{i}^{\text {measured }}
$$

For stability, the absolute value of the change in wall displacement must be less than the absolute value of the difference between the measured and required displacements. In practice, a relaxation factor, $\beta$, is used. Hence, the wall velocity at the $i+1$ cycle is

$$
\dot{s}_{i+1}^{\text {wall }}=\beta \frac{\left(\sigma_{i}^{\text {measured }}\right) / k_{\mathrm{n}}-\Delta s_{i}^{\text {measured }}}{\Delta t}
$$

where $\Delta t$ is the timestep of the $i+1$ cycle. Then, the measured stiffness at the $i$ cycle is

$$
k_{\mathrm{n}}^{\prime}=\Delta \sigma_{i}^{\text {measured }} / \Delta s_{i}^{\text {measured }}=\left(\sigma_{i}^{\text {measured }}-\sigma_{0}\right) / \Delta s_{i}^{\text {measured }}
$$


where $\Delta \sigma_{i}^{\text {measured }}$ is the increment of the current normal stress on the servo-wall with reference to the initial confining stress.

\section{RESULTS}

\section{Group-based measurement in penetration tests}

A total number of 1800 particle groups, with a size of $0.5 B \times 0.5 B$ for each group, are identified before penetration. Five particle groups (i.e., G1, G2, G3, G4, and G5) on the $30^{\text {th }}$ row counting from the bottom, 10 particle groups (i.e., G1, G6, G7, G8, G9, G10, G11, G12, G13, and G14) on the $1^{\text {st }}$ column counting from the left and 10 particle groups (i.e., G2, G15, G16, G17, G18, G19, G20, G21, G22, and G23) on the $2^{\text {nd }}$ column counting from the left are illustrated in Fig. 1b. Every particle group contains about 100 agglomerates or uncrushable disks. A particle number of 100 has been demonstrated to be sufficient to obtain a macroscopically representative value (Nitka et al. 2011). Average stress in a group is found using the averaging procedure based on the measurement logic in $\mathrm{PFC}^{2 \mathrm{D}}$ (Itasca Consulting Group Inc. 2008). The stress ratio is calculated as $\left(\sigma_{1}-\sigma_{3}\right) /\left(\sigma_{1}+\sigma_{3}\right)$, where $\sigma_{1}$ and $\sigma_{3}$ are the major and minor principal stress of the group, respectively. $\theta$ is the inclination of major principal stress counted anti-clockwise from X-axis. The volumetric strain is defined in the conventional manner as the relative change in volume, and is given by ( $n$ $\left.n_{0}\right) /(1-n)$, where $n_{0}$ is the initial porosity and $n$ is the present porosity. This definition gives dilation being positive and compression being negative. The amount of bond breakage in each particle group is quantified by the percentage of broken parallel bonds counted from the beginning of penetration. It should be pointed out that all these measurements were made on particle groups identified on the undeformed configuration prior to the pile penetration in this study. 


\section{Behavior of particle groups}

If we choose to view the pile as stationary, then the particle groups could be considered to flow towards the tip and along the shaft. Continual images of the five shaded groups on the $30^{\text {th }}$ row in high-crushable and uncrushable penetration tests, captured at every driven depth of $B$ are shown in Figure 3. In both tests, deformation of particle groups found to take place from a distance of about $3 B$ below the pile tip. The deformation then grows as these particle groups approach the tip. A larger deformation can be perceived in particle groups in the column closer to the pile. After sheared to the shaft, all groups retain the deformed shapes formed at the shoulder. Note, that particle groups on the first column are fully decomposed after sheared to the shoulder. So the data of volumetric strain, stress ratio, horizontal stress (or radial) and $\theta$ will not be presented for these groups after they pass the tip.

Fig. 4 and Fig. 5 shows evolution of volumetric strain, mobilized stress ratio, horizontal stress, $\theta$ and percentage of bonds broken of particle groups on the $1^{\text {st }}$ and $2^{\text {nd }}$ column in the high-crushable and uncrushable penetration test, respectively. The general trends of the stress-strain behavior against the normalized relative height, $h / B$ (i.e., a negative value of $h / B$ means a position below the pile tip), from Fig. 4 and Fig. 5 include $(i)$ a continuous compression from the initial position to the point with a distance of about $3 B$ below the tip for particle groups in both tests, (ii) a shearinduced dilation between $h / B \approx-3.0$ and $h / B \approx-1.5$, where the stress ratio reaches the peak, (iii) a significant volumetric compression between $h / B \approx-1.5$ and $h / B \approx 0.5$, where an abrupt strain-softening and a rapid principal stress rotation (i.e., change of sign of $\theta$ ) take place, (iv) almost all of the particle breakage events take place in particle groups in high-crushable test between $h / B \approx-1.5$ and $h / B \approx 1.0$, corresponding to the observed 
behavior in (iii), (v) all the variables remain nearly constant from $h / B \approx 3.0$ to the end of the simulation, and (vi) a more dilative behavior for particle groups in uncrushable test than those on the same column in high-crushable test. It is also noted that, for observations (iii) and (iv), there are differences in the magnitudes of each variable from different particle groups, and the trend is that the groups with a lower initial position experience a more severe strain softening and a more significant particle breakage as they pass the pile tip (i.e., $h / B \approx-1.5$ to $h / B \approx 1.0$ ). The horizontal stress reaches the peak between $h / B \approx 0.0$ and $h / B \approx 1.0$ (i.e., above the pile tip and below the pile shoulder) and remain nearly constant from $h / B \approx 3.0$ to the end of the simulation (i.e., along the pile shaft). These indicate it is the installation-induced compaction (Gandhi and Selvam 1997), but not the shear-induced dilation along shaft, that cause the increase in horizontal stress during monotonic driven. Based on the above observations, it can be concluded that the behavior of a particle group has reached the peak state below the pile tip and the critical state after it reaches the pile shaft.

\section{Influence of normal boundary condition on interface shear test}

In this section, results from numerical simulations of interface shear test under CNL, CV and CNS boundary conditions will be presented. Each test is denoted using a code of " $x-y-z$ ", where $x$ is the normal boundary condition, $y$ is the parallel bond strength (in $\mathrm{N} / \mathrm{m}$ ) and $z$ is the initial confining stress.

Fig. 6 compares $\Delta \sigma_{i}^{\text {measured }}$ versus $\Delta s_{i}^{\text {measured }}$ curve obtained in six CNS tests and includes a theoretical line indicates $k_{\mathrm{n}}=2 \times 10^{9} \mathrm{~Pa} / \mathrm{m}$. It is seen that the measured $k_{\mathrm{n}}^{\prime}$ from samples with different crushability and different initial confining stress agrees well with the target theoretical result throughout shearing. 
The particle breakage density distribution of the low-crushable sample (i.e., pb_s $=2 \times 10^{7} \mathrm{~N} / \mathrm{m}$ ) under different boundary conditions with an initial confining stress of $0.5 \mathrm{MPa}$ is shown in Fig. 7. A similar pattern is observed for tests under different boundary conditions at the same shear displacement. Particle breakage is concentrated in a narrow region above the interface and biased towards the left half of the box, in which heavily loaded contact force chains are formed. However, the percentages of breakage (or bonds broken) are not the same, the effects of which would be shown later. Figs. 8-11 show the influences of particle crushability, normal boundary condition and initial confining stress on the interface shear behavior. Specifically, Fig. 8, Fig. 9, Fig. 10 and Fig. 11 shows the effect on broken bonds, normal stress, volumetric strain, and stress ratio, respectively. The detailed discussion and interpretation of the simulation results from these figures are given below.

The percentage of parallel bonds broken relative to the total number of bonds that existed before shearing is given in Fig. 8. For low-crushable specimens under both initial confining stresses and high-crushable specimens under an initial confining stress of $0.5 \mathrm{MPa}$, the observed little difference in percentage of broken bonds under different boundary conditions is consistent with the little difference in normal stress on the servo-wall shown in Fig. 9, and in stress ratio shown in Fig. 11. Much more significant effect of the normal boundary condition is observed in high-crushability samples under an initial confining stress of $1 \mathrm{MPa}$. The percentage of bonds broken at the end of the simulation in test "CNL-1e7-1MPa" is $37.6 \%$ and $77.8 \%$ higher than that in test "CNS-1e7-1MPa" and "CV-1e7-1MPa", respectively. That means the increase of normal boundary stiffness (i.e., from CNL to $\mathrm{CNS}$ to $\mathrm{CV}$ ) reduces particle breakage in high-crushable samples. 
Corresponding to the particle breakage behavior, the effect of normal boundary condition is also clearly manifested in the normal stress on servo-wall and volumetric strain. It is evident in Fig. 9 that for an uncrushable sample (i.e., pb_s $=2 \times 10^{9} \mathrm{~N} / \mathrm{m}$ ) the increase of normal stiffness (i.e., from CNL to CNS to CV) greatly raises the normal stress measured on the servo-wall under both initial confining stresses. The rate of increase of normal stress is nearly constant with the shear displacement and roughly doubling from CNS to CV. While for the highcrushable sample under an initial confining stress of $1 \mathrm{MPa}$, the trend is opposite but much milder, with the final normal stress in CV being less than half of the initial confining stress.

The volumetric strain shown in Fig. 10 is derived from the vertical displacement of the servo-wall. It can be found that for a given sample, CNL results in a much larger change of volumetric strain than CNS, while CV strictly results in zero volume change throughout the test. Furthermore, completely opposite behaviors of volume change are observed as particle crushability changes. The uncrushable sample (i.e., $p b \_s=2 \times 10^{9} \mathrm{~N} / \mathrm{m}$ ) exhibits strong dilation while the high-crushable sample exhibits full compression. Interestingly, the low-crushable sample under an initial confining stress of $1 \mathrm{MPa}$ maintains a very slight change of volume (fluctuating around zero) throughout the test, which is largely a result of the balance between the volumetric compression caused by particle breakage and volumetric expansion caused by particle rearrangement (Wang and Yan 2013).

The stress ratio shown in Fig. 11 is calculated as $\tau / \sigma$, where $\tau$ and $\sigma$ are the shear stress and normal stress acting on the interface, respectively. The observations on the stress-strain behavior in Fig. 11 include: $(i)$ for a given sample with a fixed type of boundary condition and a fixed initial confining stress, an overall reduction of 
the mobilized stress ratio at any stage of the shearing with the increase of particle crushability, (ii) for a given sample, the different types of boundary condition results in different trends of the stress ratio behavior as particle crushability changes, and (iii) for a given type of boundary condition, an overall reduction of the peak and critical state stress ratios with increasing confining stress for crushable samples. For the uncrushable sample, the peak stress ratio reduces from CNL to CNS to CV under both initial confining stresses (Fig. 11a and 11b); while for the high-crushable sample under an initial confining stress of $1 \mathrm{MPa}$, both the peak and critical state stress ratios increase from CNL to CNS to CV (Fig. 11f). For the low-crushable sample under both initial confining stresses and the high-crushable sample under an initial confining stresses of $0.5 \mathrm{MPa}$, not much difference in the stress ratio curves is found under different types of boundary condition.

A clear understanding of the above stress ratio behavior can be readily obtained based on the observations on the particle breakage, measured normal stress on servo-wall and volumetric strain in Figs. 8-10. When the granular material is uncrushable, CNL maintains the normal stress by allowing the sample to dilate significantly. This allows the maximum obliquity of the contact force chains acting on the interface to be developed and thus the interface friction to be fully mobilized. However, CV artificially suppresses such a dilation with a consequence of a great increase of normal stress. This causes the contact force chains acting on the interface to have an obliquity less than the maximum. In other words, the interface does not have sufficient capability to mobilize a shear stress proportional to the imposed normal stress that would be achieved under the maximum obliquity condition. As a result, the mobilized stress ratio decreases from CNL to CNS to CV for an uncrushable sample. 
In the case of high-crushability material under a higher confining stress (i.e., 1 $\mathrm{MPa}$ ), particle breakage leads to the lowest normal stress in CV and the highest normal stress in CNL. This is accompanied by a decreasing amount of volumetric compression from CNL to CNS to (zero in) CV (Fig. 10b). The interface has the fully capability to mobilize the shear stress proportional to the imposed normal stress in each case. Therefore, under this condition, the decreasing stress ratio from CV to CNS to $\mathrm{CNL}$ is purely a result of decreasing normal stress on the servo-wall. Lastly, in the case of low-crushability material under both confining stresses and high-crushability material under a lower confining stress (i.e., $0.5 \mathrm{MPa}$ ), there is very little difference between or small change in the absolute value of the three variables under any type of boundary condition (Figs. 8-10). As a result, the mobilized stress ratio is also very similar for the three cases.

\section{DISCUSSION}

We now make a comparison between the pile penetration behavior and interface shear behavior based on the above simulation results. As shown in Figs. 3-5, for the high-crushable and uncrushable penetration tests, the stress-strain pattern is similar for both soil types. An overall contractive behavior occurs for particle groups, though a shear-induced dilation occurs between $h / B \approx-3.0$ and $h / B \approx-1.5$ (i.e., below the pile tip). This is consistent with the monotonic increase of the horizontal stress in particle groups from the initial position to the point immediately above the pile tip $(0.0<h / B<1.0)$. This indicates that the influence of particle crushability on the volume and horizontal stress change is partly offset by the installation-induced compaction. While in interface shear tests, both the shear-induced contraction and 
dilation can be found. The degree of contraction or dilation depends on the particle crushability, initial confining stress and the normal boundary condition.

In penetration tests, the behavior of a particle group has reached the peak state below the pile tip. All the variables measured in particle groups close to the pile shaft remain nearly constant from $h / B \approx 3.0$ to the end of the simulation in both tests. This indicates that the behavior of a particle group has reached the critical state after it reaches the pile shaft. An abrupt strain-softening occurs between these two states, when a particle group flows past the pile tip. As discussed above, the influence of normal boundary condition on the critical state stress ratio is not obvious for most of the cases. $\tau / \sigma$ along part of the pile shaft from the point with a distance of $3 B$ above the tip to the point with a distance of $7 B$ above the tip (Fig. 1a) recorded at a driven depth of $21 B$ is also included in Fig. 11. The normal stress on this part of pile shaft at a driven depth of $21 B$ is within the range of $0.5 \mathrm{MPa} \sim 1 \mathrm{MPa}$. The stress ratio on the pile shaft is smaller than the stress ratio measured in interface shear test at critical state under any type of normal boundary condition. One of the main differences between particle groups in penetration test and soil in interface shear test is the existence of previous stress paths of soil before being sheared to the pile shaft, whose effects on the interface shear behavior of sand has been investigated by a number of authors (e.g., Vaid et al. 1990; Evgin and Fakharian 1996; Fakharian and Evgin 2000; Gennaro et al. 2004; Gomez et al. 2008; Lee et al. 2011). Although Evgin and Fakharian (1996) found that the coefficient of friction was independent from few types of stress paths by performing interface shear tests under different normal boundary conditions, others (Vaid et al. 1990; Gennaro et al. 2004) concluded that the critical state was dependent on the stress path. This is most likely due to the influence of complex stress paths and particle breakage on the possible change of the location of 
the critical state line (Bandini and Coop 2011), which was not taken into consideration in the work of Evgin and Fakharian (1996). The numerical results in this study and a previous study (Liu and Wang 2016) both show that the penetration makes the soil element (i.e., particle groups) move in a complex stress path, undergo an loading and unloading process, and a large rotation of the principal stresses. The more complicated stress-strain path of the particle group in penetration test is believed to be the main cause of the loss of friction at the pile shaft. In order to roughly simulate the pile installation, Lehane and White (2005) gave a number of shearing cycles to samples in interface shear tests before testing. Figure 12 shows an example of the cyclic behavior from an interface shear test of "CNL-1e7-0.5MPa". The shear displacement is reversed at $0 \mathrm{~mm}$ and $15 \mathrm{~mm}$. The stress ratio at critical state from the $2^{\text {nd }}$ cycle is generally lower than that from the $1^{\text {st }}$ cycle. The degradation of the skin friction of pile shaft, therefore, reflects the effects of stress path on the behavior of interface shearing.

\section{CONCLUSION}

This study endeavors to investigate the effects of normal boundary condition in interface shear tests and the initial state of sand on the pile shaft resistance behavior. Through the careful construction of the pile penetration model and the interface shear test under three types of boundary conditions (CV, CNS and CNL) and analyzing the results, it is found that the upper normal boundary has impact on the stress value, volumetric strain, percentage of bonds broken, and stress ratio. Specifically, from CNL to $\mathrm{CNS}$ to $\mathrm{CV}$, the stress increases with other variables decreasing in the uncrushable sample, while the stress and volumetric strain decreases with other variables increasing in the high-crushable medium dense sample under an initial 
confining stress of $1 \mathrm{MPa}$. In general, an increase in the normal boundary stiffness would result in a larger change in normal stress and a smaller change in volumetric strain. Additionally, an obvious influence of the normal boundary condition on the critical state friction coefficient was only found in high-crushable sample under an initial confining stress of $1 \mathrm{MPa}$. For the case of high-crushable sample under an initial confining stress of $0.5 \mathrm{MPa}$ and low-crushable sample under any initial confining stress, there is little difference between or small change in the absolute values of percentage of broken bonds, normal stress and volumetric strain under any type of boundary conditions. As a result, the mobilized stress ratio is also very similar for these cases.

During installation, the behavior of a particle group has reached the peak state below the pile tip and the critical state after it reaches the pile shaft. The peak state, which can be observed in the interface shear tests, cannot be found along the pile shaft during installation. The influence of normal boundary condition on the stress ratio at the critical state is not obvious. Therefore, there is not much difference in determining the friction coefficient of pile shaft during installation by interface shear test under different types of normal boundary condition. As a consequence, the conventional interface shear test (i.e., CNL) can provide valuable information about friction coefficient on the determination of skin friction along pile shaft.

\section{ACKNOWLEDGEMENTS}

The study presented in this article was supported by the General Research Fund CityU122813 from the Research Grant Council of the Hong Kong SAR, National Science Foundation of China (NSFC) grant No. 51379180 and the open- 
research grant No. SLDRCE15-04 from State Key Laboratory of Civil Engineering Disaster Prevention of Tongji University.

\section{REFFERENCES}

Arshad, M. I., Tehrani, F. S., Prezzi, M., and Salgado, R. 2014. Experimental study of cone penetration in silica sand using digital image correlation. Géotechnique, 64(7): 551-569.

Bandini, V., and Coop, M. R. 2011. The influence of particle breakage on the location of the critical state line of sands. Soils and Foundations, 51(4): 591-600.

Cheng, Y. P., Nakata, Y., and Bolton, M. D. 2003. Discrete element simulation of crushable soil. Géotechnique, 53(7): 633-641.

Chow, F. C., Jardine, R. J., Nauroy, J. F., and Brucy, F. 1997. Time-related increases in the shaft capacities of driven piles in sand. Géotechnique, 47(2): 353-361.

DeJong, J. T., White, D. J., and Randolph, M. F. 2006. Microscale observation and modeling of soil-structure interface behavior using particle image velocimetry. Soils and Foundations, 46(1): 15-28.

Di Donna, A., Ferrari, A., and Laloui, L. 2016. Experimental investigations of the soil-concrete interface: physical mechanisms, cyclic mobilization, and behaviour at different temperatures. Canadian Geotechnical Journal, 53(4): 659-672.

Evgin, E., and Fakharian, K. 1996. Effect of stress paths on the behavior of sand-steel interfaces. Canadian Geotechnical Journal, 33(6): 853-865.

Fakharian, K., and Evgin, E. 1997. Cyclic simple-shear behavior of sand-steel interfaces under constant normal stiffness condition. Journal of Geotechnical and Geoenvironmental Engineering, 123(12): 1096-1105. 
Fakharian, K., and Evgin, E. 2000. Elasto-plastic modelling of stress-path-dependent behavior of interfaces. International Journal for Numerical and Analytical Methods in Geomechanics, 24(2): 183-199.

Frost, J. D., DeJong, J. T., and Recalde, M. 2002. Shear failure behavior of granularcontinuum interfaces. Engineering Fracture Mechanics, 69(17): 2029-2048.

Gandhi, S. R., and Selvam, S. 1997. Group effect on driven piles under lateral load. Journal of Geotechnical and Geoenvironmental Engineering, 123(8): 702-709.

Gavin, K. G., and O'Kelly, B. C. 2007. Effect of friction fatigue on pile capacity in dense sand. Journal of Geotechnical and Geoenvironmental Engineering, 133(1):63-71.

Gennaro, V. D., Canou, J., Dupla, J. C., and Benahmed, N. 2004. Influence of loading path on the undrained behavior of a medium loose sand. Canadian Geotechnical Journal, 41(1): 166-180.

Gomez, J. E., Filz, G. M., Ebeling, R. M., and Dove, J. E. 2008. Sand-to-concrete interface response to complex load paths in a large displacement shear box. Geotechnical Testing Journal, 31(4): 1-12.

Itasca Consulting Group. 2008. Guide book: theory and background PFC2D. Technical report. Itasca Consulting Group, Inc.

Jardine, R. J., Zhu, B. T., Foray, P., and Yang, Z. X. 2013. Interpretation of stress measurements made around closed-ended displacement piles in sand. Géotechnique, 63(8): 613-627.

Jiang, M. J., Konrad, J. M., and Leroueil, S. 2003. An efficient technique for generating homogeneous specimens for DEM studies. Computers and Geotechnics, 30(7): 579-597. 
Jiang, Y., Xiao, J., Tanabashi, Y., and Mizokami, T. 2004. Development of an automated servo-controlled direct shear apparatus applying a constant normal stiffness condition. International Journal of Rock Mechanics and Mining Sciences, 41(2): 275-286.

Johnston, I. W., Lam, T. S. K., and Williams, A. F. 1987. Constant normal stiffness direct shear testing for socketed pile design in weak rock. Géotechnique, 37(1): 83-89.

Lee, M., Choi, S., Kim, M., and Lee, W. 2011. Effect of stress history on CPT and DMT results in sand. Engineering Geology, 117(3-4): 259-265.

Lehane, B. M. 1992. Experimental investigations of pile behaviour using instrumented field piles. $\mathrm{PhD}$ thesis, Imperial College, London.

Lehane, B. M., and White, D. J. 2005. Lateral stress changes and shaft friction for model displacement piles in sand. Canadian Geotechnical Journal, 42(4): 10391052.

Lehane, B. M., Gaudin, C., and Schneider, J. A. 2005. Scale effects on tension capacity for rough piles buried in dense sand. Géotechnique, 55(10): 709-719.

Lehane, B. M., Jardine, R. J., Bond, A., and Frank, R. 1993. Mechanisms of shaft friction in sand from instrumented pile tests. Journal of Geotechnical Engineering, 119(1): 19-35.

Liu, S., and Wang, J. 2016. Depth-independent cone penetration mechanism by a DEM-based stress normalization approach. Canadian Geotechnical Journal, 53(5): 871-883.

Nitka, M., Combe, G., Dascalu, C., and Desrues, J. 2011. Two-scale modeling of granular materials: a DEM-FEM approach. Granular Matter, 13(3): 277-281. 
Ooi, L. H., and Carter, J. P. 1987. A constant normal stiffness direct shear device for static and cyclic loading. Geotechnical Testing Journal, 10(1): 3-12.

Peng, S. Y., Ng, C. W. W., and Zheng, G. 2014. The dilatant behaviour of sand-pile interface subjected to loading and stress relief. Acta Geotechnica, 9(3): 425-437.

Porcino, D., Fioravante, V., Ghionna, V. N., and Pedroni, S. 2003. Interface behavior of sands from constant normal stiffness direct shear tests. Geotechnical Testing Journal, 26(3): 1-13.

Randolph, M. F., Carter, J. P., and Wroth, C. P. 1979. Driven piles in clay-the effects of installation and subsequent consolidation. Géotechnique, 29(4): 361-393.

Tabucanon, J. T., Airey, D. W., and Poulos, H. G. 1995. Pile skin friction in sands from constant normal stiffness tests. Geotechnical Testing Journal, 18(3): 350364.

Tehrani, F. S., Han, F., Salgado, R., Prezzi, M., Tovar, R. D., and Castro, A. G. 2016. Effect of surface roughness on the shaft resistance of non-displacement piles embedded in sand. Géotechnique, 66(5): 386-400.

Uesugi, M., Kishida, H., and Tsubakihara, Y. 1988. Behavior of sand particles in sand-steel friction. Soils and Foundations, 28(1): 107-118.

Vaid, Y. P., Chung, E. K. F., and Kuerbis, R. H. 1990. Stress path and steady state. Canadian Geotechnical Journal, 27(1): 1-7.

Wang, J., and Yan, H. B. 2012. DEM analysis of energy dissipation in crushable soils. Soils and Foundations, 52(4): 644-657.

Wang, J., and Yan, H. B. 2013. On the role of particle breakage in the shear failure behavior of granular soils by DEM. International Journal for Numerical and Analytical Methods in Geomechanics, 37(8): 832-854. 
Wang, J., Dove, J. E., and Gutierrez, M. S. 2007a. Anisotropy-based failure criterion for interphase systems. Journal of Geotechnical and Geoenvironmental Engineering, 133(5): 599-608.

Wang, J., Dove, J. E., and Gutierrez, M. S. 2007b. Determining particulate-solid interphase strength using shear-induced anisotropy. Granular Matter, 9(3): 231240.

Wang, J., and Zhao, B. 2014. Discrete-continuum analysis of monotonic pile penetration in crushable sands. Canadian Geotechnical Journal, 51(10): 10951110.

White, D. J., and Bolton, M. D. 2004. Displacement and strain paths during planestrain model pile installation in sand. Géotechnique, 54(6): 375-397.

White, D. J., and Lehane, B. M. 2004. Friction fatigue on displacement piles in sand. Géotechnique, 54(10):645-658.

Yang, Z. X., Jardine, R. J., Zhu, B. T., Foray, P., and Tsuha, C. H. C. 2010. Sand grain crushing and interface shearing during displacement pile installation in sand. Géotechnique, 60(6): 469-482.

\section{List of Tables}

Table 1 - Input parameters for DEM simulations

\section{List of Figures}

Fig. 1 - (a) model geometry of penetration tests; (b) layout of the predefined groups before penetration; (c) pile shaft surface consisting of asperities and pile tip; (d) a 
typical agglomerate composed of parallel-bonded disks; (e) model geometry of interface shear test.

Fig. 2 - Interface shear test under constant normal stiffness boundary condition.

Fig. 3 - Continual images of (a) G1, (b) G2, (c) G3, (d) G4, and (e) G5 in highcrushable penetration test; and (f) G1, (g) G2, (h) G3, (i) G4, and (j) G5 in uncrushable penetration test captured every driven depth of $B$, viewing the pile as stationary; (k) a set of close-up images of G2 at various selected driven depths in high-crushable penetration test.

Fig. 4 - Evolution of volumetric strain, mobilized stress ratio, horizontal stress, $\theta$, and percentage of bonds broken of particle groups on the (a) $1^{\text {st }}$, and (b) $2^{\text {nd }}$ column in the high-crushable penetration test.

Fig. 5 - Evolution of volumetric strain, mobilized stress ratio, horizontal stress, and $\theta$ of particle groups on the (a) $1^{\text {st }}$, and (b) $2^{\text {nd }}$ column in the uncrushable penetration test. Fig. $6-\Delta \sigma_{i}^{\text {measured }}$ versus $\Delta s_{i}^{\text {measured }}$ obtained in CNS tests under an initial confining stress of (a) $0.5 \mathrm{MPa}$ and (b) $1 \mathrm{MPa}$.

Fig. 7 - Distributions of particle breakage density at shear displacement of (a) $5 \mathrm{~mm}$, (b) $10 \mathrm{~mm}$, and (c) $15 \mathrm{~mm}$ in "CV-2e7-0.5MPa" test; (d) $5 \mathrm{~mm}$, (e) $10 \mathrm{~mm}$, and (f) 15 $\mathrm{mm}$ in "CNL-2e7-0.5MPa " test; (g) $5 \mathrm{~mm}$, (h) $10 \mathrm{~mm}$, and (i) $15 \mathrm{~mm}$ in "CNS-2e7$0.5 \mathrm{MPa} "$ test.

Fig. 8 - Effects of particle crushability and boundary condition on broken bonds under an initial confining stress of (a) $0.5 \mathrm{MPa}$ and (b) $1 \mathrm{MPa}$.

Fig. 9 - Effects of particle crushability and boundary condition on normal stress under an initial confining stress of (a) $0.5 \mathrm{MPa}$ and (b) $1 \mathrm{MPa}$.

Fig. 10 - Effects of particle crushability and boundary condition on volumetric strain under an initial confining stress of (a) $0.5 \mathrm{MPa}$ and (b) $1 \mathrm{MPa}$. 
Fig. 11 - Effects of normal boundary condition on mobilized stress ratio in (a) uncrushable, (c) low-crushable, and (e) high-crushable samples under an initial confining stress of 0.5 MPa, and (b) uncrushable, (d) low-crushable, and (f) highcrushable samples under an initial confining stress of $1 \mathrm{MPa}$.

Fig. 12 - Stress ratio versus shear displacement from a cyclic interface shear test of “CNL-1e7-0.5MPa". 
(a)

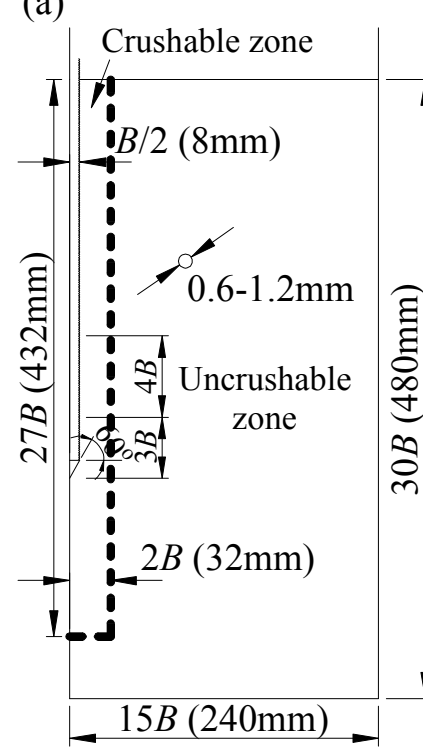

(b)

(c)

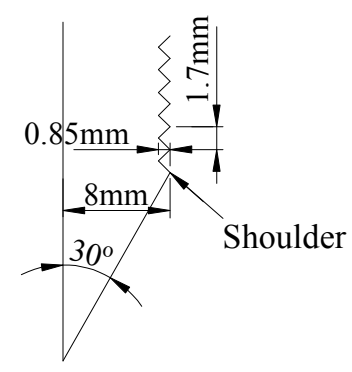

$1^{\text {st }}$ column

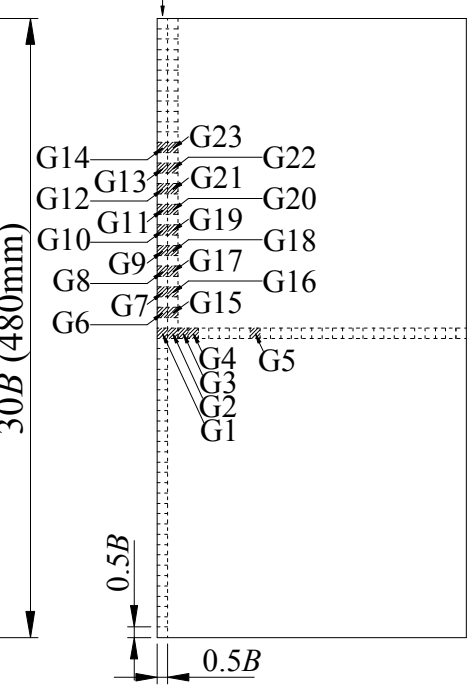

(d)

(e)
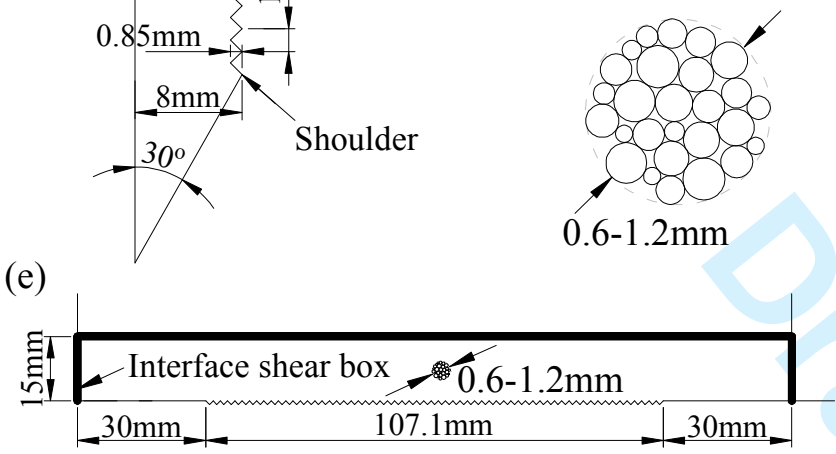

Fig. 1. (a) model geometry of penetration tests; (b) layout of the predefined groups before penetration; (c) pile shaft surface consisting of asperities and pile tip; (d) a typical agglomerate composed of parallel-bonded disks; (e) model geometry of interface shear test. 


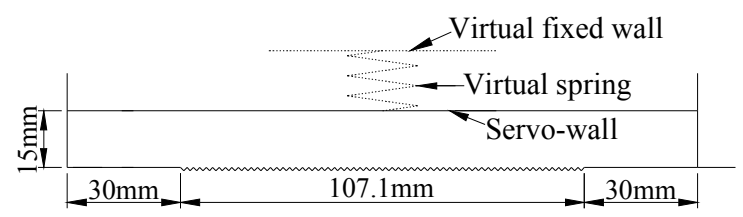

Fig. 2. Interface shear test under constant normal stiffness boundary condition. 
(a) (b) (c)

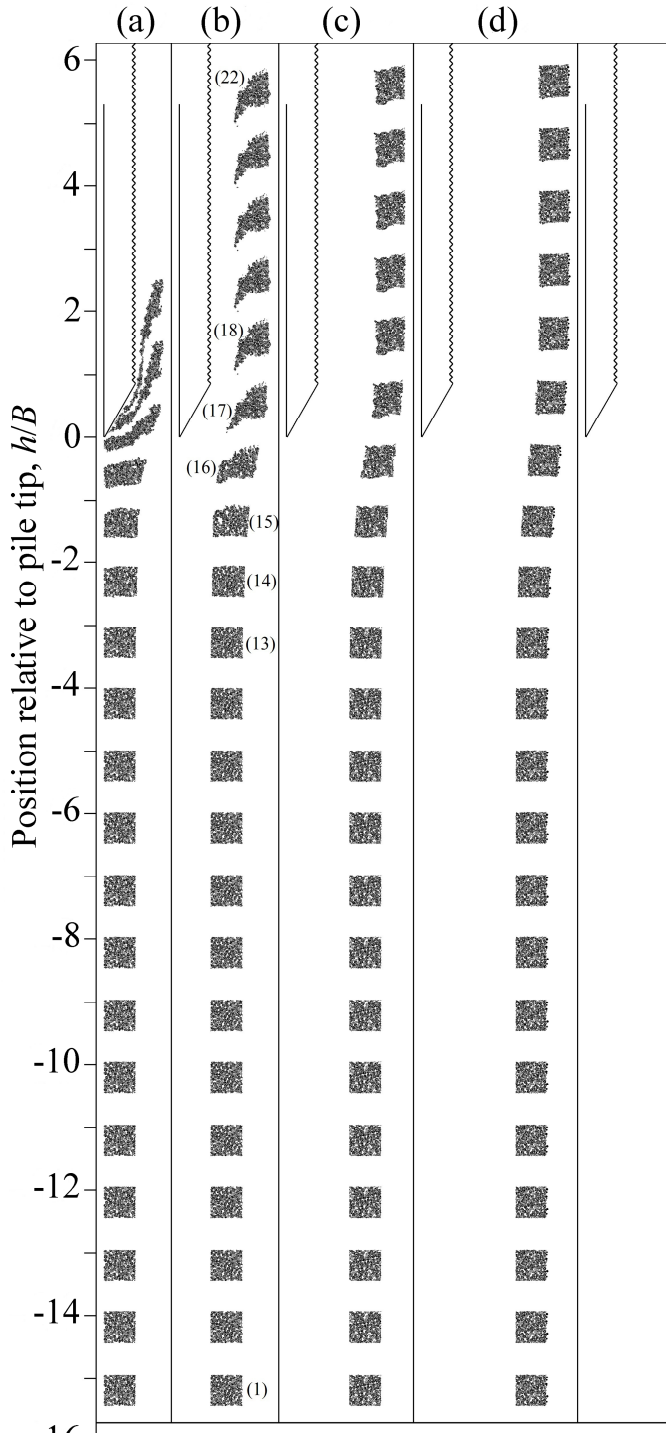

(e)

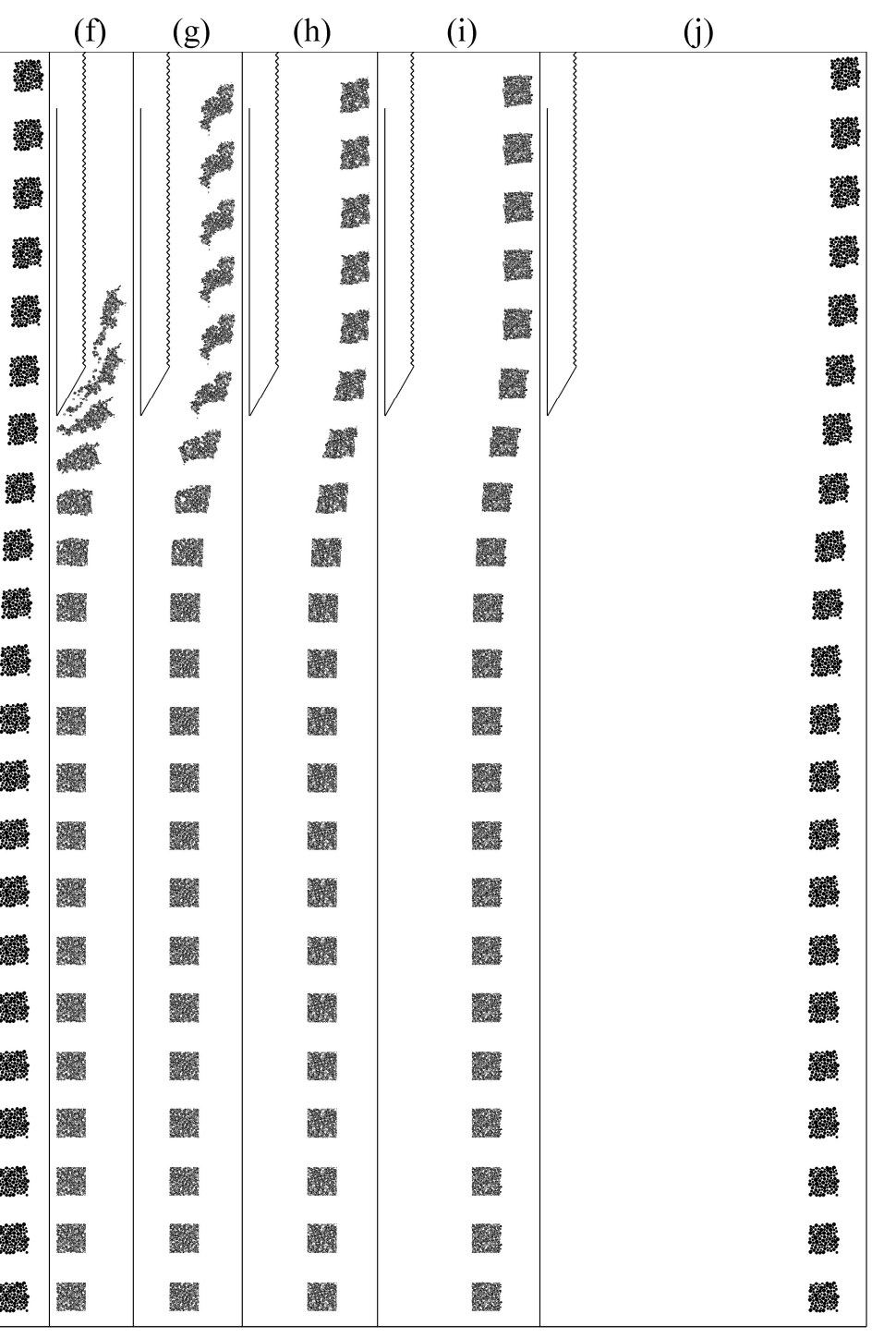

(e)

(k)

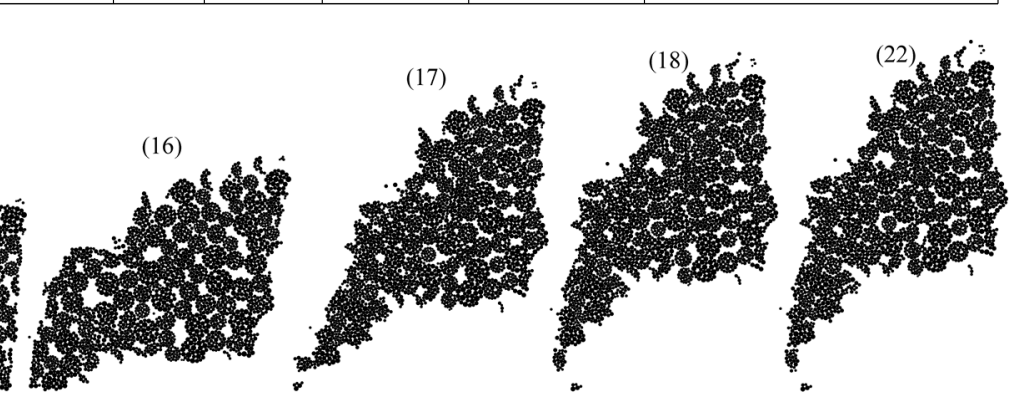

Fig. 3. Continual images of (a) G1, (b) G2, (c) G3, (d) G4, and (e) G5 in high-crushable penetration test; and (f) G1, (g) G2, (h) G3, (i) G4, and (j) G5 in uncrushable penetration test captured every driven depth of $B$, viewing the pile as stationary; (k) a set of close-up images of G2 at various selected driven depths in high-crushable penetration test. 
(a)
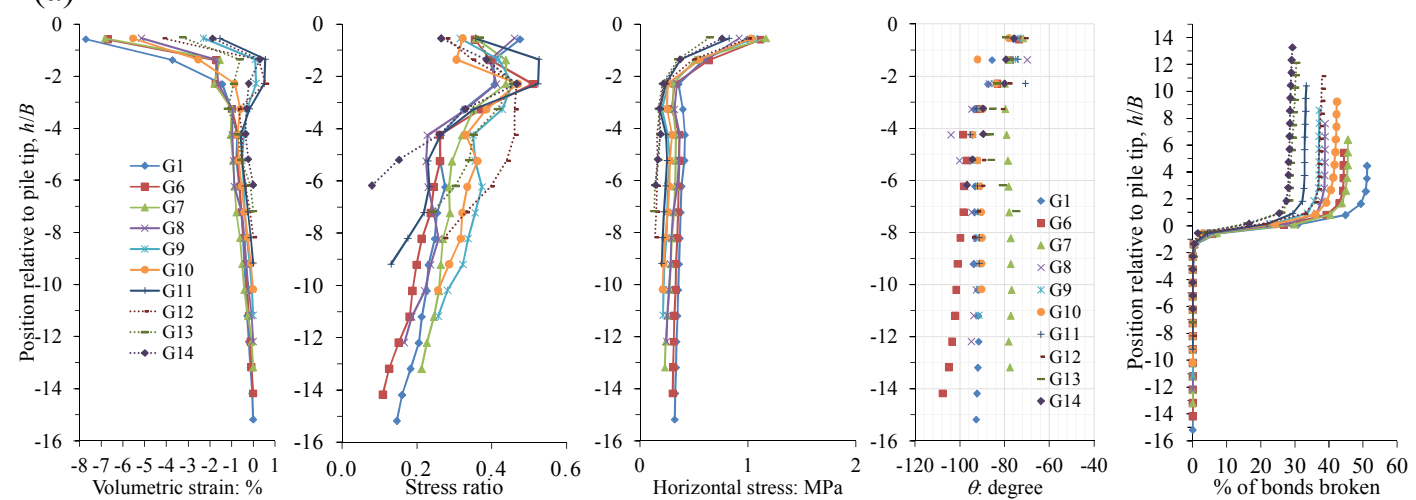

(b)
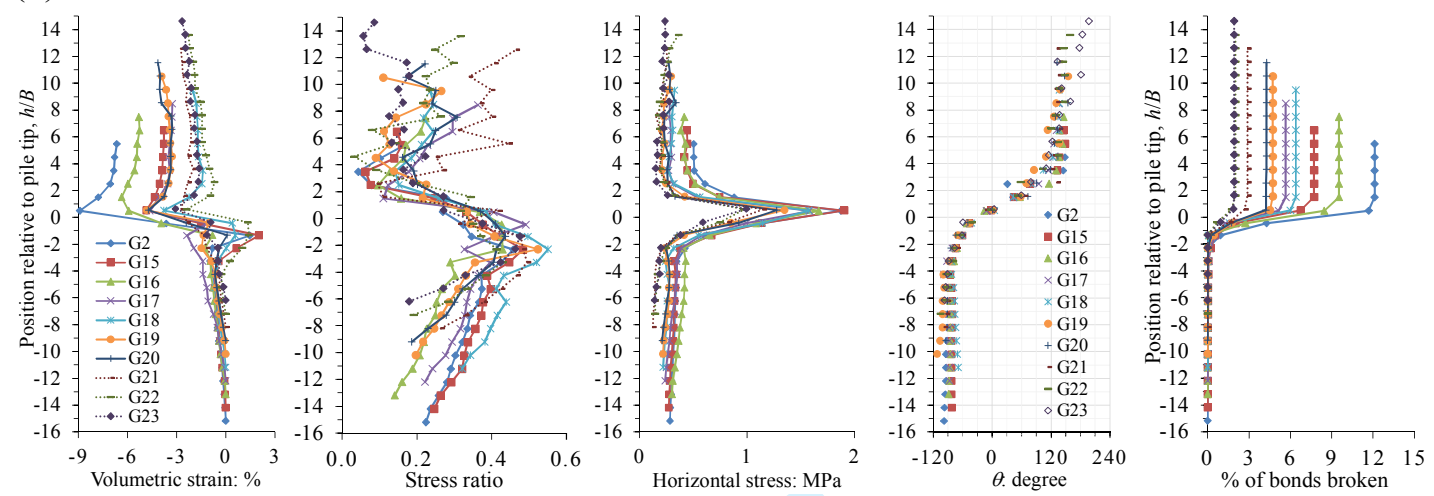

Fig. 4. Evolution of volumetric strain, mobilized stress ratio, horizontal stress, $\theta$, and percentage of bonds broken of particle groups on the (a) $1^{\text {st }}$, and (b) $2^{\text {nd }}$ column in the high-crushable penetration test. 
(a)
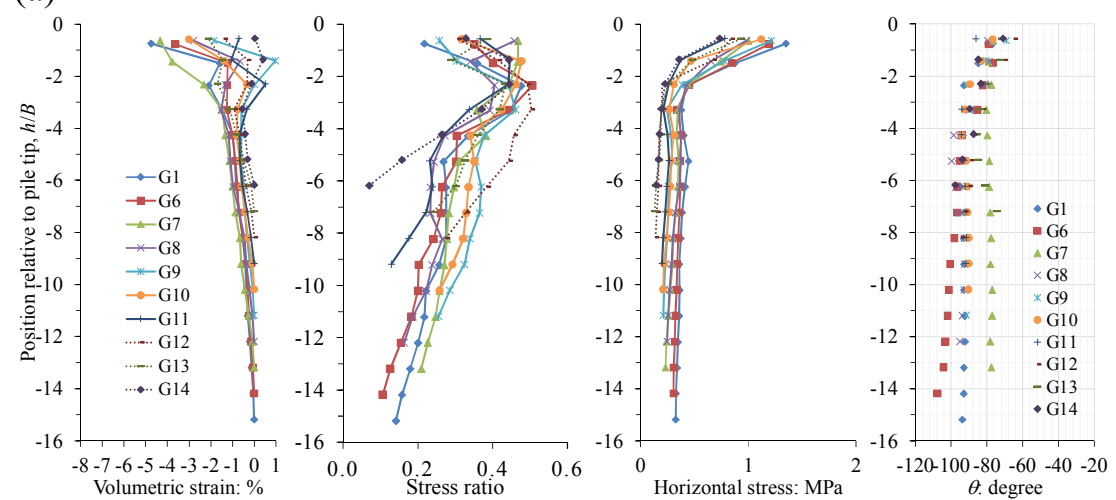

(b)
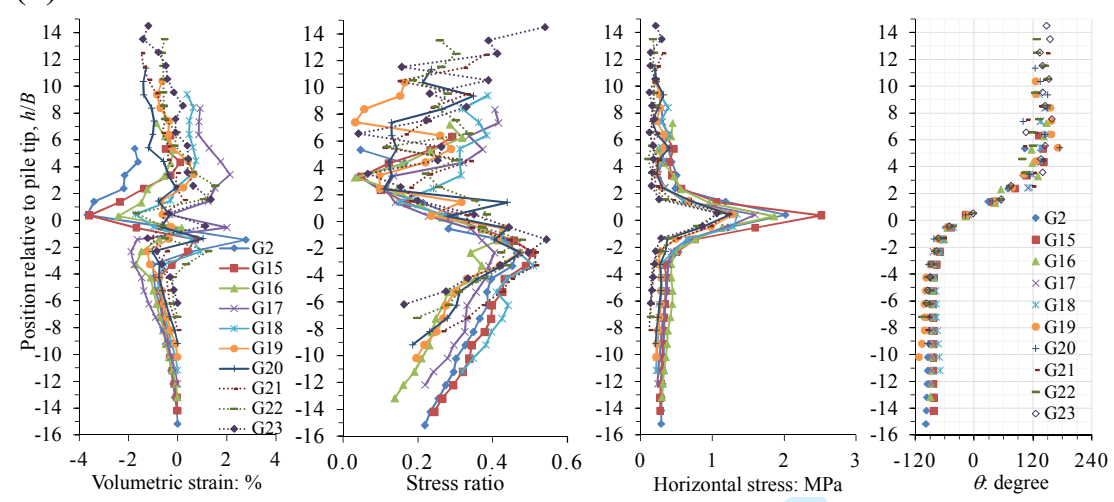

Fig. 5. Evolution of volumetric strain, mobilized stress ratio, horizontal stress, and $\theta$ of particle groups on the (a) $1^{\text {st }}$, and (b) $2^{\text {nd }}$ column in the uncrushable penetration test. 
(a)

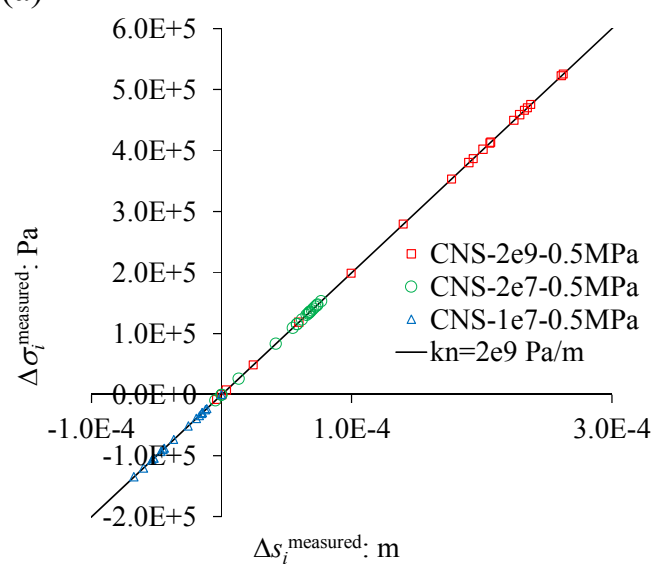

(b)

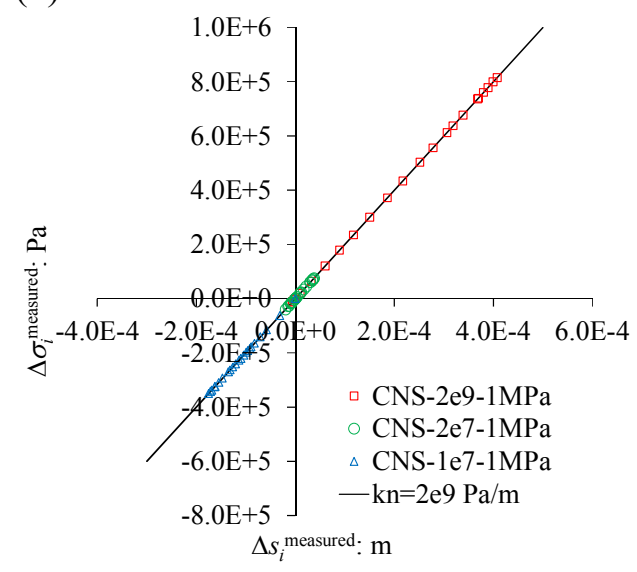

Fig. 6. $\Delta \sigma_{i}^{\text {measured }}$ versus $\Delta s_{i}^{\text {measured }}$ obtained in CNS tests under an initial confining stress of (a) $0.5 \mathrm{MPa}$ and (b) $1 \mathrm{MPa}$. 
(a)

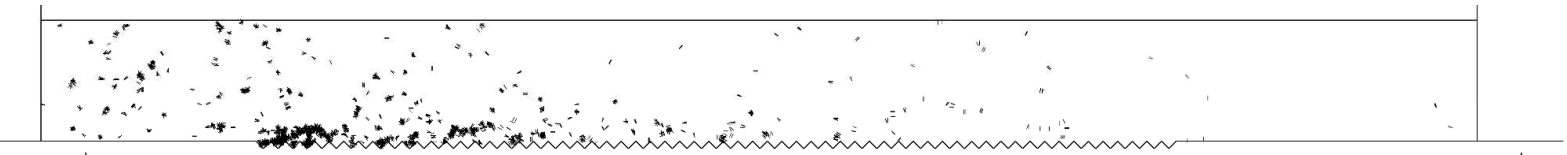

(b)

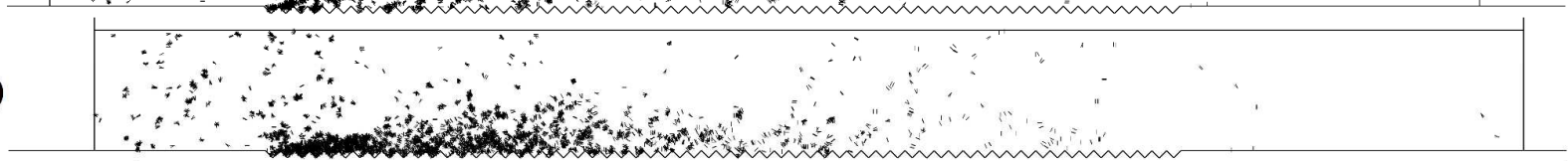

(c)

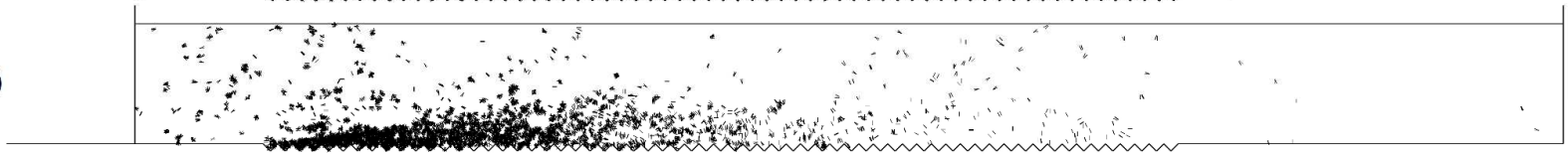

(d)

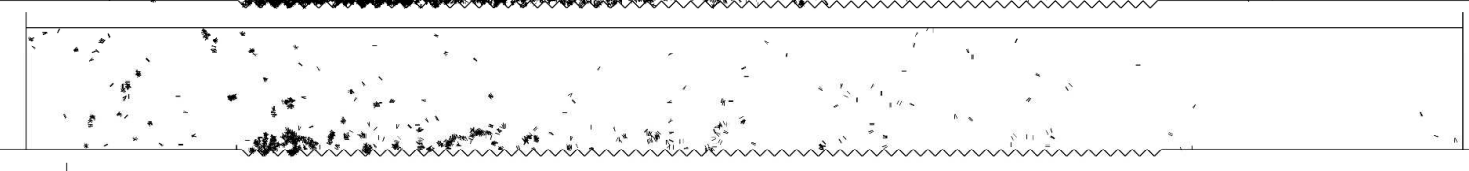

(e)

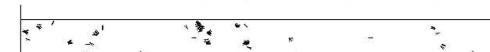

(f)

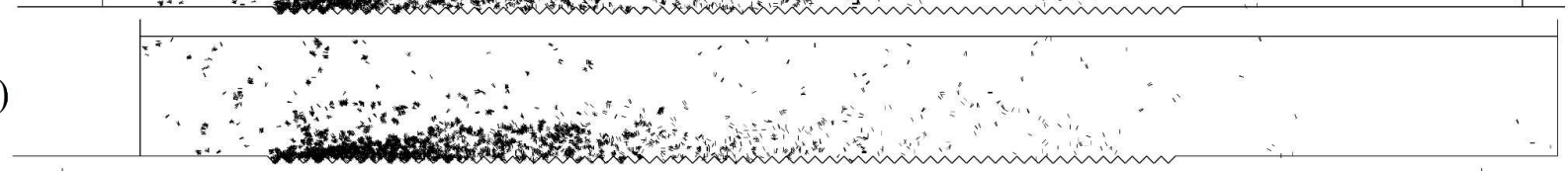

(g)

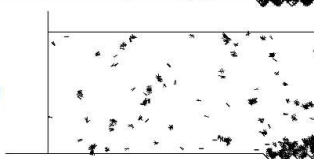

(h)

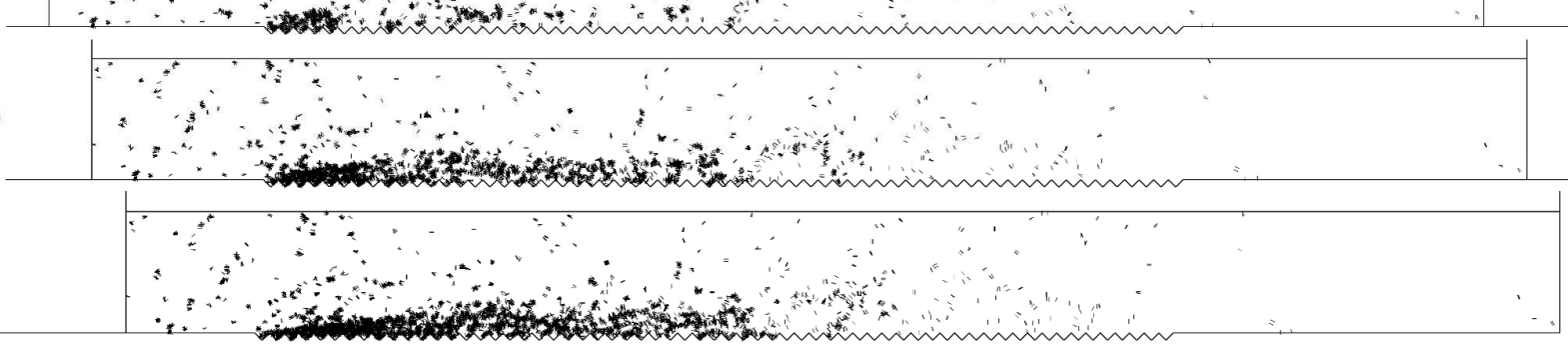

Fig. 7. Distributions of particle breakage density at shear displacement of (a) $5 \mathrm{~mm}$, (b) $10 \mathrm{~mm}$, and (c) 15 $\mathrm{mm}$ from "CV-2e7-0.5MPa"; (d) $5 \mathrm{~mm}$, (e) $10 \mathrm{~mm}$, and (f) $15 \mathrm{~mm}$ from "CNL-2e7-0.5MPa"; (g) $5 \mathrm{~mm}$, (h) $10 \mathrm{~mm}$, and (i) $15 \mathrm{~mm}$ from "CNS-2e7-0.5MPa". 
(a)

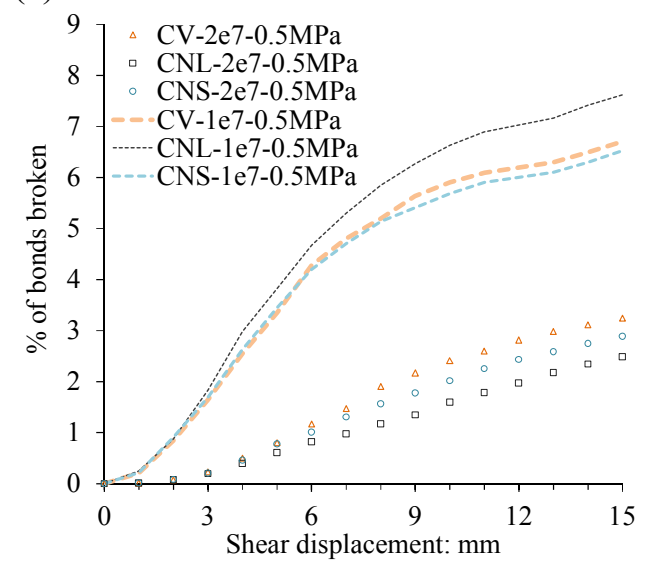

(b)

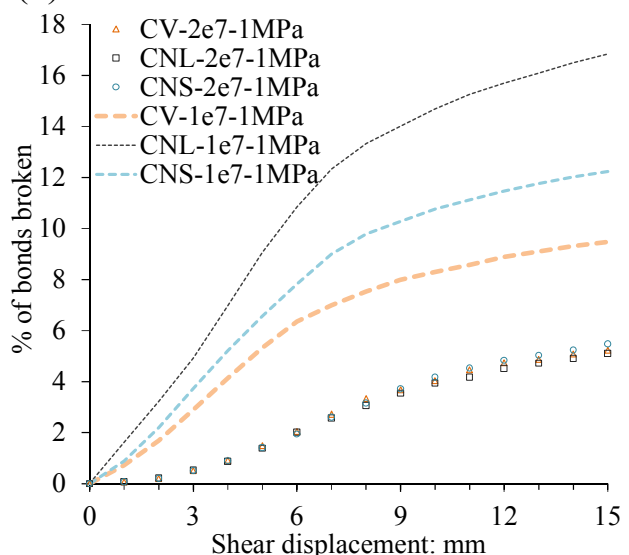

Fig. 8. Effects of particle crushability and boundary condition on broken bonds under an initial confining stress of (a) $0.5 \mathrm{MPa}$ and (b) $1 \mathrm{MPa}$. 
(a)

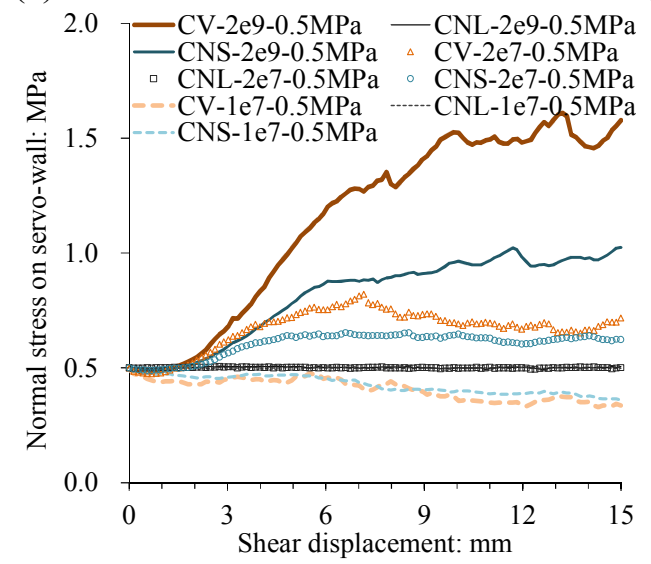

(b)

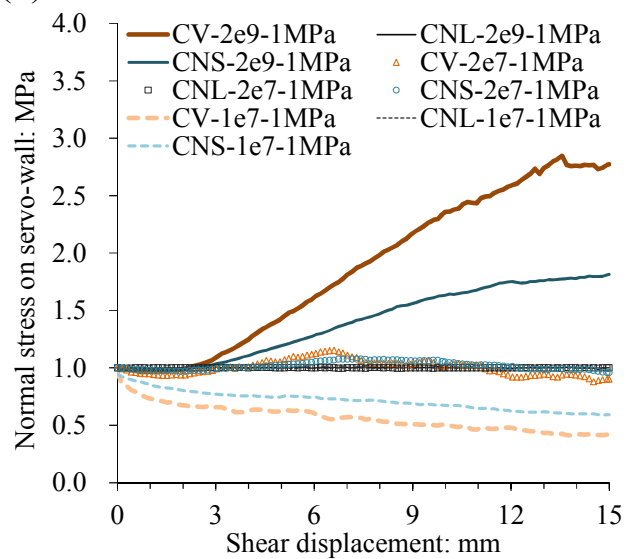

Fig. 9. Effects of particle crushability and boundary condition on normal stress under an initial confining stress of (a) $0.5 \mathrm{MPa}$ and (b) $1 \mathrm{MPa}$. 
(a)

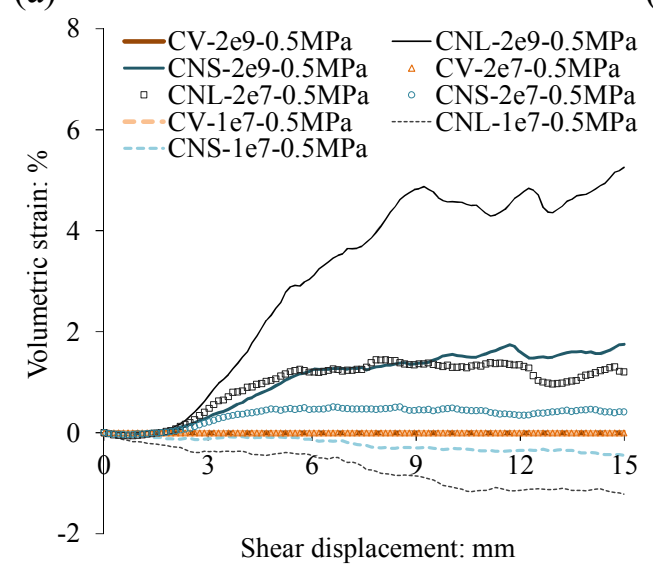

(b)

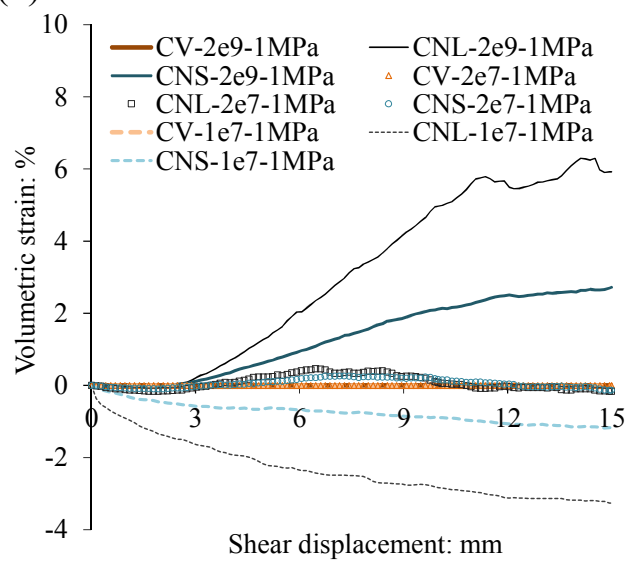

Fig. 10. Effects of particle crushability and boundary condition on volumetric strain under an initial confining stress of (a) $0.5 \mathrm{MPa}$ and (b) $1 \mathrm{MPa}$. 
(a)

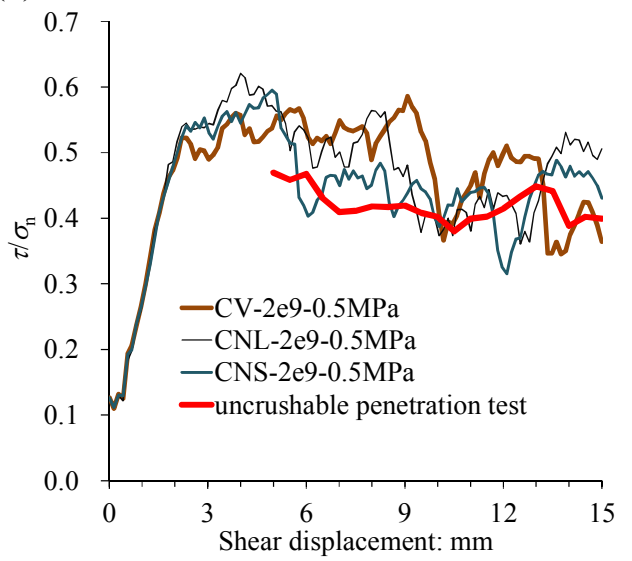

(c)

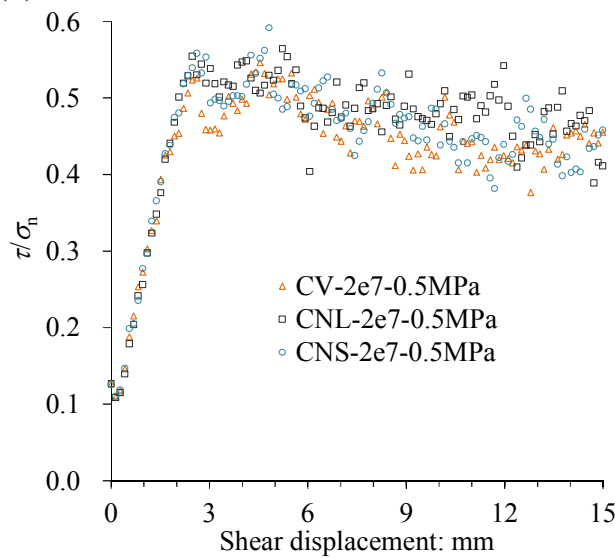

(e)

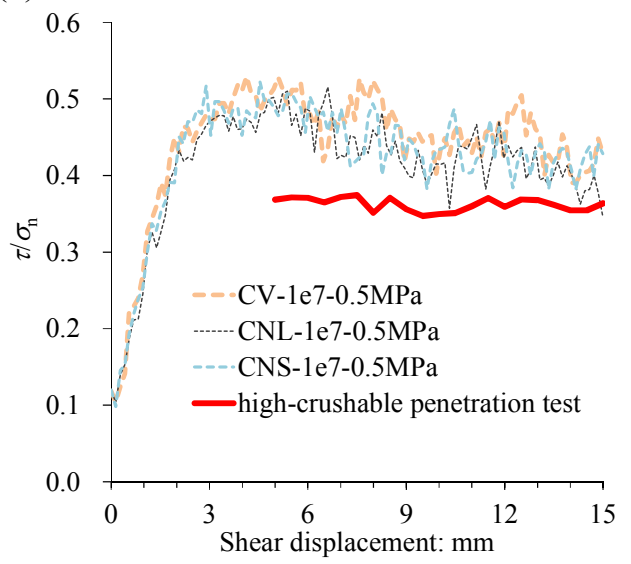

(b)

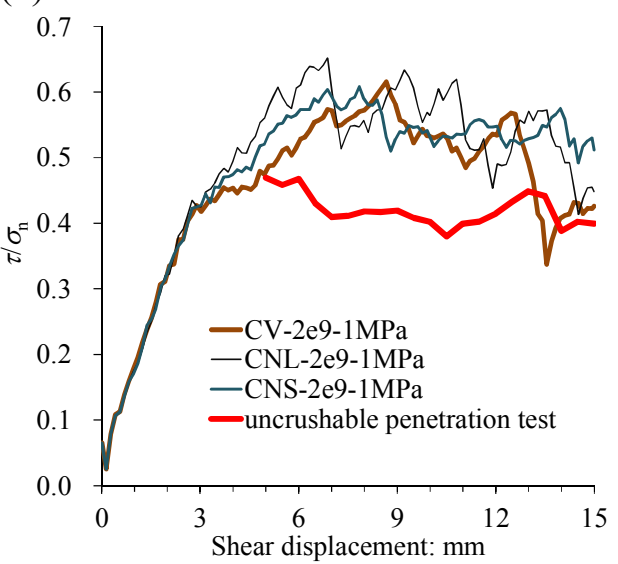

(d)

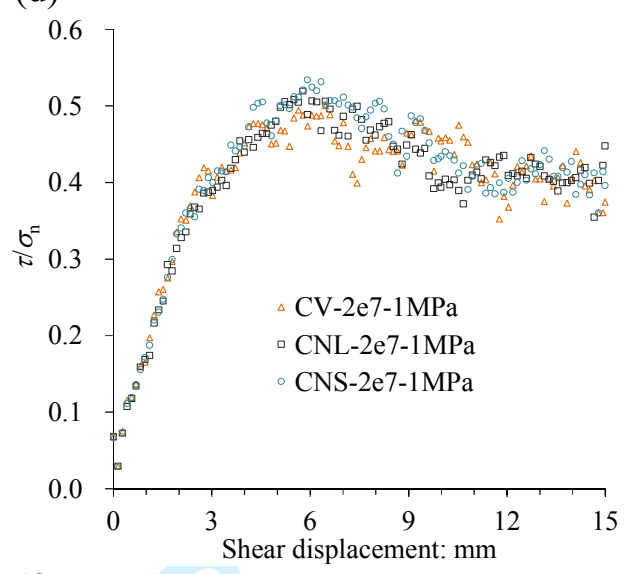

(f)

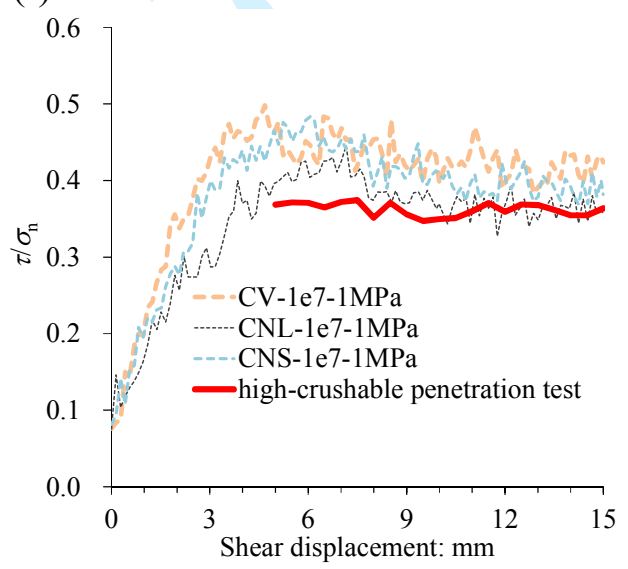

Fig. 11. Effects of normal boundary condition on mobilized stress ratio in (a) uncrushable, (c) low-crushable, and (e) high-crushable samples under an initial confining stress of $0.5 \mathrm{MPa}$; and (b) uncrushable, (d) low-crushable, and (f) high-crushable samples under an initial confining stress of $1 \mathrm{MPa}$. 


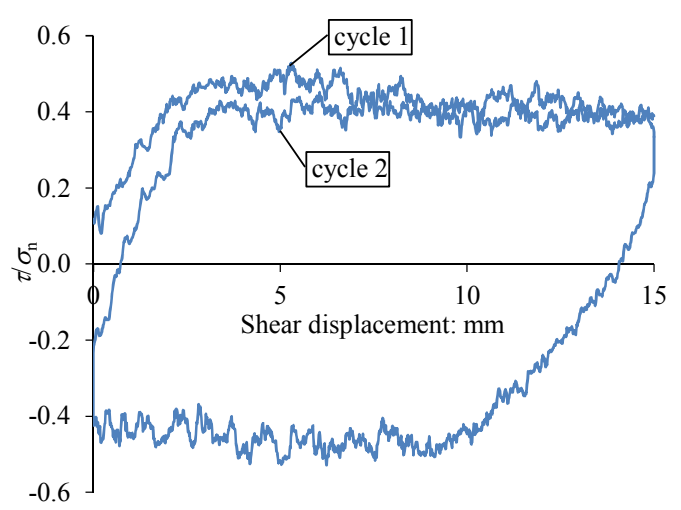

Fig. 12. Stress ratio versus shear displacement from a cyclic interface shear test of "CNL-1e7-0.5MPa". 
Table 1. Input parameters for DEM simulations

\begin{tabular}{ccc}
\hline Parameter & $\begin{array}{c}\text { Interface shear } \\
\text { test; crushable } \\
\text { zone of } \\
\text { penetration test }\end{array}$ & $\begin{array}{c}\text { Uncrushable } \\
\text { zone of } \\
\text { penetration } \\
\text { test }\end{array}$ \\
\hline Diameters of agglomerates $(\mathrm{mm})$ & $0.6-1.2$ & $0.6-1.2$ \\
Diameters of elementary disks $(\mathrm{mm})$ & $0.069-0.278$ & -- \\
Density of disk $\left(\mathrm{Kg} / \mathrm{m}^{3}\right)$ & 2650 & 2200 \\
Normal and shear stiffnesses of disk $(\mathrm{N} / \mathrm{m})$ & $4 \mathrm{e}^{8}$ & $4 \mathrm{e}^{8}$ \\
Normal and shear stiffnesses of wall $(\mathrm{N} / \mathrm{m})$ & $4 \mathrm{e}^{8}$ & $4 \mathrm{e}^{8}$ \\
Friction coefficient of disk & 0.5 & 0.5 \\
Friction coefficient of asperity wall & 0.5 & 0.5 \\
Normal and shear parallel-bond strengths $\left(\mathrm{N} / \mathrm{m}^{2}\right)$ & $1 \mathrm{e}^{7}, 2 \mathrm{e}^{7}, 2 \mathrm{e}^{9}$ & -- \\
Normal and shear parallel-bond stiffnesses & $1.5 \mathrm{e}^{12}$ & -- \\
(N/m $\left.{ }^{3}\right)$ & & -- \\
Ratio of parallel bond radius to disk radius & 0.5 & -- \\
Relaxation factor $(\beta)$ in CNS & 0.1 & - \\
\hline
\end{tabular}

